\title{
Out-patient geriatric assessment by a hospital- based general practitioner: Results and financial implications
}

\author{
Anette Hylen Ranhoff, MD, PhD \\ Department of Medicine, County Hospital of Kristiansund, Norway \\ Address for correspondence: Department of Medicine, Ullevaal Hospital, N-0407 Oslo, Norway \\ telephone +4722119000 telefax +4722119181 e-mail anettehylen.ranhoff@ulleval.no
}

\begin{abstract}
Norway has few specialists in geriatric medicine, but geriatric services are supposed to be implemented in all local hospitals. I assessed a model for hospital out-patient geriatric service headed by a general practitioner. The service was organised in a local hospital. 266 elderly patients were referred for geriatric assessment.

Main outcome measures were ICD-9 diagnostic categories, general patient well-being before and after assessment, patients' and referring doctors' satisfaction, and cost of the service and income received.

Age, gender and diagnoses were within the same range as in other studies of out-patient geriatric assessment. Two hundred and three (85.3\%) out of 238 patients reached in follow-up interviews were satisfied with the service and reported improved general well-being. Referring doctors reported satisfaction with the service. The service was financed by charges paid by the patients and a capitation fee from the social security. Cost per patient was £ 94 (1070 NOK).

The study shows that in Norway a GP can implement an outpatient geriatric service which improves the patients' general well-being and is cost effective.
\end{abstract}

Key words: general practitioner, geriatric assessment, financial implications, local hospital, out-patient clinic, patient well-being

\section{INTRODUCTION}

The provision of a specialist geriatric service has proven to reduce loss of function in frail elderly patients and diminish stress on carers [1,2]. In Norway, elderly people with failing health are primarily the responsibility of general practitioners (GPs) and are referred to general or organ-specialized hospital departments as necessary. Geriatric services are limited; there are 62 specialists in geriatric medicine, and only 44 of these work in hospitals. Most local hospitals and seven of 19 counties have no such services.

In 1985/86, the Norwegian health authorities recommended that geriatric services should be provided in all hospitals, and suggested various models for such services [3]. One of these proposals related to smaller hospitals, allowing hospital-based general practitioners to head smaller teams for the provision of out-patient geriatric assessment. In this article I describe the implementation and results of such a service.

\section{MATERIALS AND METHODS}

The Out-patient Clinic for the Elderly was located at Kristiansund Hospital. At the time of the study, the catchment area for this hospital encompassed 12 municipalities with 45,000 inhabitants, 4,750 of whom were 75 years of age or older [4]. The hospital had departments of surgery, gynecology, and internal medicine with a total of 128 beds. The staff included several branch specialists, as well as psychiatric expertise, an ophthalmologist and an otorhinolaryngologist with an audiology laboratory. The hospital was equipped with a laboratory and a X-ray department with a CT scanner.

\section{Staffing and mode of operation}

The out-patient clinic was staffed two days a week with a GP (the author) who had experience in general practice and had taken several courses in geriatric medicine, a registered nurse and a secretary. A physiotherapist, an occupational therapist and a dietician could be called upon when necessary, but they did not see all the patients. The service was organized under the Medical Department. Advice on complicated geriatric problems was given by the Department of Geriatric Medicine, University of Oslo.

Close cooperation with the hospital doctors made it possible for a patient to be seen by various specialists 
on the same day so as to assess multiple problems. Some of the patients were also seen in their homes by one or more of the team members.

The consultations were typical for geriatric medicine with assessment of functions and need for care as well as traditional diagnostic work-up. Routines employed in the out-patient clinics of the university departments of geriatric medicine in Oslo and Bergen were used, and the recommendations by Rubinstein et al. [5] and Lachs et al. [6] were followed. Diagnoses were only recorded when a disease interfered with function or well-being, or created a need for referral, treatment or provision of services. The International Classification of Diseases (ICD-9) was used [7]. Written case summaries were always sent to the referring doctors.

At the day of the consultation and before the patient was seen by the doctor or other members of the team, the secretary asked the patients how his or her general well-being had been during the last two weeks. On average three months later (range 1-6), a second interview, concerning well-being and general satisfaction with the service, was carried out either when the patient met for another consultation or over the telephone. General well-being was scored 1 to 5 on an ordinal scale (1, very good; 5, very poor) [8]. McNemar's test, with exact methodology, was used to compare these ratings. General satisfaction with the service was scored 1 to 3 on an ordinal scale (1, satisfied; 2, fairly satisfied; and 3, dissatisfied). The patients were also asked whether their health problems had improved, were unchanged or had worsened.

Prior to the start of the service, the 55 GPs in the area were sent a postal questionnaire regarding the need for geriatric services. At the end of the study they were asked about their satisfaction with the service in another postal questionnaire.

Costs and income figures related to the service were provided by the hospital accountant.

\section{RESULTS}

Before the service was started, $30(54.5 \%)$ of the 55 GPs in the catchment area responded to a postal questionnaire regarding the need for such a service. Of these, $22(73.3 \%)$ stated a perceived need for a better diagnostic service for elderly people with problems like general loss of function and mental impairment, and also for assessment of requirements for rehabilitation and care. As a result of this, the GPs and hospital doctors were invited by letter to refer elderly patients with geriatric problems of this type to the out-patient clinic.

\section{Characteristics of the patients}

During the period from 1 January 1990 to 1 October 1991, 266 referred patients were assessed. The mean age was 79.3 years (range 64-99), 215 (80.8\%) were women, 156 (58.6\%) lived alone, and 162 (60.9\%) received help from outside the household (home help, $116(43.6 \%)$ and home nursing, $55(20.7 \%))$.

The most frequent causes of referral were mental impairment $(66,24.8 \%)$, patient suffering from multiple medical problems $(45,16.9 \%)$, chronic pain $(30,11.3 \%)$, or general loss of function $(26,9.8 \%)$. A health check had been requested for 37 (13.9\%). These subjects were significantly younger (mean age 77.2 years vs. 79.7, $\mathrm{P}=0.022$ on the Mann-Whitney test) and not typical geriatric patients. Six patients got no diagnosis, while for 164 more than one diagnosis was made. The mean number of diagnoses for all patients was 1.9. The most frequent ones were dementia (46, $18.4 \%)$ and osteoarthritis $(44,16.5 \%)$. Urinary incontinence was found in $34(12.8 \%)$, but only two of these were referred for it. In 16 patients $(6.0 \%)$, glaucoma was detected or proven to be insufficiently treated, and all these cases were confirmed by an ophthalmologist.

\section{Resulting interventions}

Five patients (1.9\%) were admitted as hospital inpatients, and $101(38.0 \%)$ were referred to other specialists (most frequently an ophthalmologist, an audiologist or an orthopaedic surgeon). Referral for treatment by a physiotherapist, a dietician or an occupational therapist was always made if suggested by any of the team-members. For five patients, a permanent place in a nursing home or home for the elderly was recommended, while a further $23(8.6 \%)$ were referred for short-term stay in a nursing home or rehabilitation center.

\section{Findings at the follow-up}

A standardized interview was carried out with 238 $(89.5 \%)$ of the patients (or a close companion of theirs) within 1-6 months after the consultation. At this point, $13(4.9 \%)$ had died, and another 15 were lost to follow up. For 52 patients, this type of data was provided by an informant (relative 41 , home nurse 4 , home help 2, others 5). Most of the respondents, 203 $(85.3 \%)$, stated that they were satisfied with the service. To the question "Have your health problems improved since you were seen at the outpatient clinic?", $75(32.9 \%, 95 \%$ CI $26.8-39.0)$ stated that their health had improved, $120(52.6 \%, 95 \%$ CI $42.2-59.1)$ that it was unchanged, and $33(14.5 \%, 95 \% \mathrm{CI} 9.9-19.1)$ that it had worsened. New health problems were reported by 42 patients.

Among the patients able to reply for themselves, general well-being was significantly improved $(\mathrm{P}<0.001$ on McNemar's test). Of the 37 patients reporting poor or very poor overall well-being before the consultation, $29(78.4 \%)$ scored higher at the followup, and of the 124 scoring fair or better before assessment, only $11(8.9 \%)$ scored poor and none very poor at the follow-up interview (Table 1). 
Table 1. General well-being before and after assessment and intervention ( $\left.\mathrm{N}=161^{*}\right)$.

\begin{tabular}{lcccccccr}
\hline & \multicolumn{9}{c}{ After intervention } & & \\
\cline { 2 - 6 } & Very good & Good & Fair & Poor & Very poor & Total & $(\%)$ \\
\hline Before intervention & & & & & & & & \\
$\quad$ Very good & 8 & 4 & 0 & 1 & 0 & 13 & $(8.1)$ \\
Good & 18 & 29 & 8 & 6 & 0 & 61 & $(37.9)$ \\
Fair & 15 & 19 & 12 & 4 & 0 & 50 & $(31.1)$ \\
Poor & 7 & 12 & 8 & 7 & 0 & 34 & $(21.1)$ \\
Very poor & 0 & 0 & 2 & 1 & 0 & 3 & $(1.9)$ \\
\hline Total & 48 & 64 & 30 & 19 & 0 & 161 & $(100)$ \\
$(\%)$ & $(29.8)$ & $(39.8)$ & $(18.6)$ & $(11.8)$ & $(0)$ & $(100)$ & \\
\hline
\end{tabular}

* Response only from patients able to reply for themselves.

\section{The referring doctors' satisfaction}

In 1992, $31(56.4 \%)$ of the 55 GPs practising in the area at that time replied to another postal questionnaire regarding their satisfaction with the service. In all, 26 GPs had referred patients to the service and all but one considered the service to be useful for geriatric patients.

\section{The financial implications}

In 1991, 170 patients had full geriatric assessment while 60 patients had simple consultations with the doctor, and 177 came for follow-up. Time used for geriatric assessment was 340 hours, and the cost per patient receiving full geriatric assessment was £ 94 (1070 NOK). The income came from charges paid by the patients and a capitation fee from social security (Table 2). The time spent on geriatric assessment by the whole team was approximately 2 hours per patient, and approximately 30 minutes for follow-ups and simple consultations without multidisciplinary assessment. The cost of rooms and income resulting from our patients being referred to other units in the hospital - e.g. charges paid by patients in the X-ray department - are excluded.

\section{DISCUSSION}

The GPs' answers to the postal questionnaire before the service was started indicated a need for a geriatric service in this area. The patients' age and sex distribution and the diagnoses made covered much the same range as found in other studies of out-patient geriatric assessment $[2,9]$. The diagnoses were, however, not confirmed by a specialist geriatrician. The assessment revealed a number of disorders not mentioned by the referring doctor, e.g. urinary incontinence and glaucoma.
Table 2. Income and cost of service in 1991.

\begin{tabular}{|c|c|c|c|}
\hline \multicolumn{2}{|l|}{ Income } & NOK & $£$ \\
\hline \multicolumn{2}{|l|}{ Payment by patients } & 34.500 & 3.030 \\
\hline \multicolumn{2}{|c|}{ Capitation fees from social security } & 216.050 & 18.950 \\
\hline \multicolumn{2}{|l|}{ Total } & 250.550 & 21.980 \\
\hline Cost & Hours per week & NOK & $£$ \\
\hline Physician & 10 & 67.000 & 5.880 \\
\hline Nurse & 10 & 52.000 & 4.560 \\
\hline Secretary & 15 & 78.000 & 6.840 \\
\hline Physiotherapist & 2 & 13.000 & 1.140 \\
\hline Occupational therapist & 2 & 12.000 & 1.050 \\
\hline Dietician & 1 & 6.000 & 530 \\
\hline Miscellaneous expenses & & 13.000 & 1.140 \\
\hline Travels & & 4.250 & 370 \\
\hline Total & & 245.250 & 21.510 \\
\hline
\end{tabular}

* $1 £=11.4$ NOK (average exchange rate in 1991)

Patients' replies to the questions about health and general well-being indicated that an improvement had taken place after being seen at the out-patient clinic (Table 1). However, owing to the uncontrolled design of the study, it cannot be inferred whether this resulted from the assessment and interventions made, merely from spontaneous recovery, or from the subjects wanting to please the interviewer. Furthermore, my results have not been compared with what would have been achieved by a specialist geriatrician under the similar circumstances. A proper scientific testing of the achievements of a service like this would imply a large, multicentre trial with a number of hospitals randomized to have either a hospital-based GP or a proper specialist in charge of the geriatric outpatient clinic. Of course, this would be very costly and not at all feasible in Norway, which has so few geriatricians.

To train the number of specialist geriatricians necessary to implement geriatrics in all local hospitals 
in Norway would take a long time, even if it were possible. This study indicates that a GP with support from university-based geriatricians can implement a hospital out-patient geriatric service which improves the health of the patients and is cost effective for the hospital. However, it has no bearing on the question of the provision of geriatric hospital beds, which are also a necessity for effective geriatric care.

\section{ACKNOWLEDGEMENTS}

The study was funded by the Norwegian National Health Organization and the Norwegian National Board of Health. Professor Knut Laake and Dr. Torgeir B. Wyller have been helpful in revising the manuscript. I am also grateful to the staff in Kristiansund Hospital for their enthusiastic approach to our elderly patients.

\section{REFERENCES}

1. Stuck AE, Siu AL, Wieland GD, Adams J, Rubenstein LZ. Comprehensive geriatric assessment: a meta analysis of controlled trials. Lancet 1993; 342: 1032-6.

2. Silverman M, Musa D, Martin DC, Lave JR, Adams J, Ricci EM. Evaluation of outpatients' geriatric assessment: a randomized multi-site trial. J Am Geriatr Soc 1995; 43: 733-40.

3. Proposition no. $48(1985 / 86)$ to the Odelsting: Nursing homes in health and social service in the communes. Oslo: Norwegian Government Administration Service, 1986.

4. Statistics Norway. Statistical Yearbook 1985-93. Oslo: Statistics Norway, 1994.

5. Rubinstein LV, Calkins DR, Greenfield S, Jette AM, Meenan RF, Nevins MA, et al. Health status assessment for elderly patients. Report of the Society of General Internal Medicine Task Force on Health Assessment. $J$ Am Geriatr Soc 1989; 37: 562-9.

6. Lachs MS, Feinstein AR, Cooney LM, Drickamer MA, Marottoli RA, Pannill FC, et al. A simple procedure for general screening for functional disability in elderly patients. Ann Intern Med 1990; 112: 699-706.

7. Manual of the International Statistical Classification of Diseases, Injuries, and Causes of Death. Oslo: Statistics Norway, 1986.

8. Spilker B (ed.). Quality of Life Assessments in Clinical Trials. New York: Raven Press, 1990: 3-9.

9. Epstein AM, Hall JA, Fretwell M, Feldstein M, DeCiantis ML, Tognetti J, et al. Consultative geriatric assessment for ambulatory patients. JAMA 1990; 263: 538-44. 